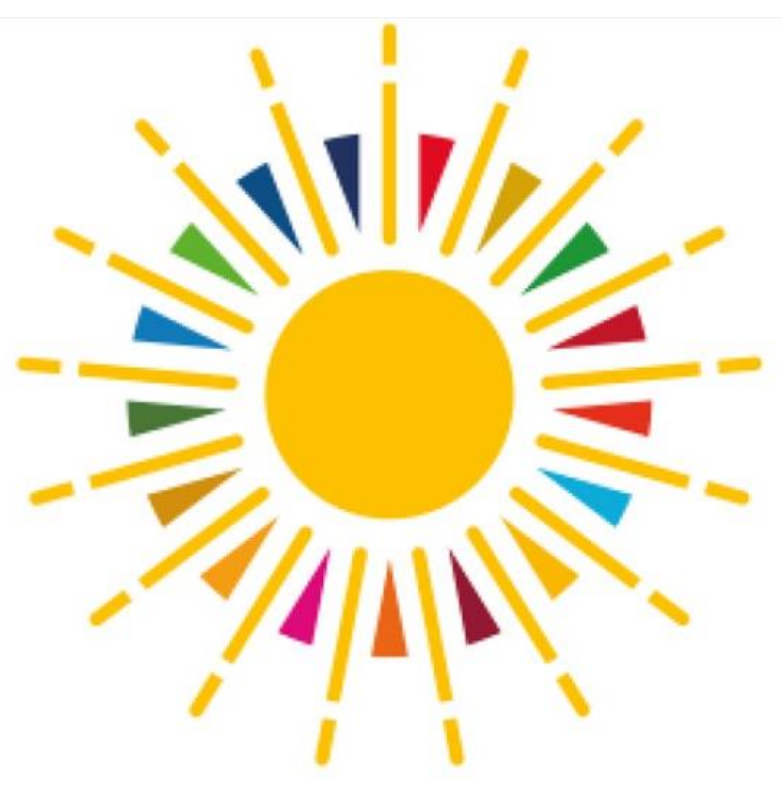

\title{
16 de mayo, Día Internacional de la Luz
}

El Día Internacional de la Luz (DIL) es un evento internacional administrado por el Programa Internacional de Ciencia Básica (IBSP) de la UNESCO. A nivel internacional está gestionado desde el International Day of Light Secretariat (https://www.lightday.org/). Se trata de una iniciativa global que promueve una celebración anual para incrementar el conocimiento que la sociedad tiene del papel crucial que la ciencia de la luz y las tecnologías de la luz representan en el mundo actual, en campos tan diversos como la medicina, las comunicaciones, la producción de energía, la agricultura, la biología, la astronomía, etc.

El DIL abarca todos los aspectos que tienen que ver con la luz en el sentido más general, incluyendo el arte, la cultura o el desarrollo sostenible. La celebración del DIL es por tanto un legado permanente del exitoso 2015 - Año Internacional de la Luz y de las Tecnologías de la Luz que, una vez al año, nos recordará la relevancia que la ciencia y la tecnología de la luz tienen en nuestras vidas.

En España, se coordina desde el Comité Español del Día Internacional de la Luz, que agrupa a los principales agentes relacionados con la ciencia y tecnología de la luz, tales como sociedades científicas, centros de investigación, universidades, consorcios y plataformas tecnológicas, empresas, etc. Desde SEDOPTICA, como sociedad científica española cuya actividad está específicamente centrada en el campo de la Óptica y la Fotónica, participamos muy activamente en el Comité Español del Día de la Luz. Una de las acciones importantes ha sido la puesta en marcha de la página web oficial española del Día Internacional de la Luz (https://www.diadelaluz.es) a través de la cual está disponible toda la información sobre actividades realizadas, así como numerosos recursos y materiales asociados, que puede emplearse para realización de actividades. En esta web cualquier persona puede también inscribirse para recibir noticias y alertas relacionadas, así como anunciar actividades que tenga previsto realizar. 
El DIL se celebrará el 16 de mayo de cada año, en conmemoración de la primera emisión de luz láser el 16 de mayo de 1960, obtenida por Theodore Maiman con un láser de rubí. Justamente el láser es un ejemplo paradigmático de cómo un descubrimiento científico relacionado con la luz proporciona herramientas revolucionarias para el beneficio global de la sociedad, en las comunicaciones, en las tecnologías de la salud y muchas otras aplicaciones en múltiples campos.

La primera celebración del Día Internacional de la Luz tendrá lugar el día 16 de mayo de 2018, en la Sede General de UNESCO en Paris. En España, el Acto Central de celebración tendrá lugar ese mismo día en la Facultad de Ciencias Físicas de la Universidad Complutense de Madrid. No obstante, el DIL tiene un propósito global, y se prevé la realización de otras numerosas actividades en España alrededor del día 16 de mayo. El DIL cuenta ya con numerosos patrocinadores y mecenas que se han implicado en el éxito de esta celebración en España.

Desde aquí animamos a todos los miembros de SEDOPTICA y a toda la comunidad de Óptica y Fotónica en España a participar en este evento mediante la organización de actividades.

María J. Yzuel

Presidenta del Comité Español del DIL

\section{Ignacio Moreno}

Presidente de SEDOPTICA y Vicepresidente del Comité Español del DIL

\section{Patrocinadores y mecenas del DIL en España}

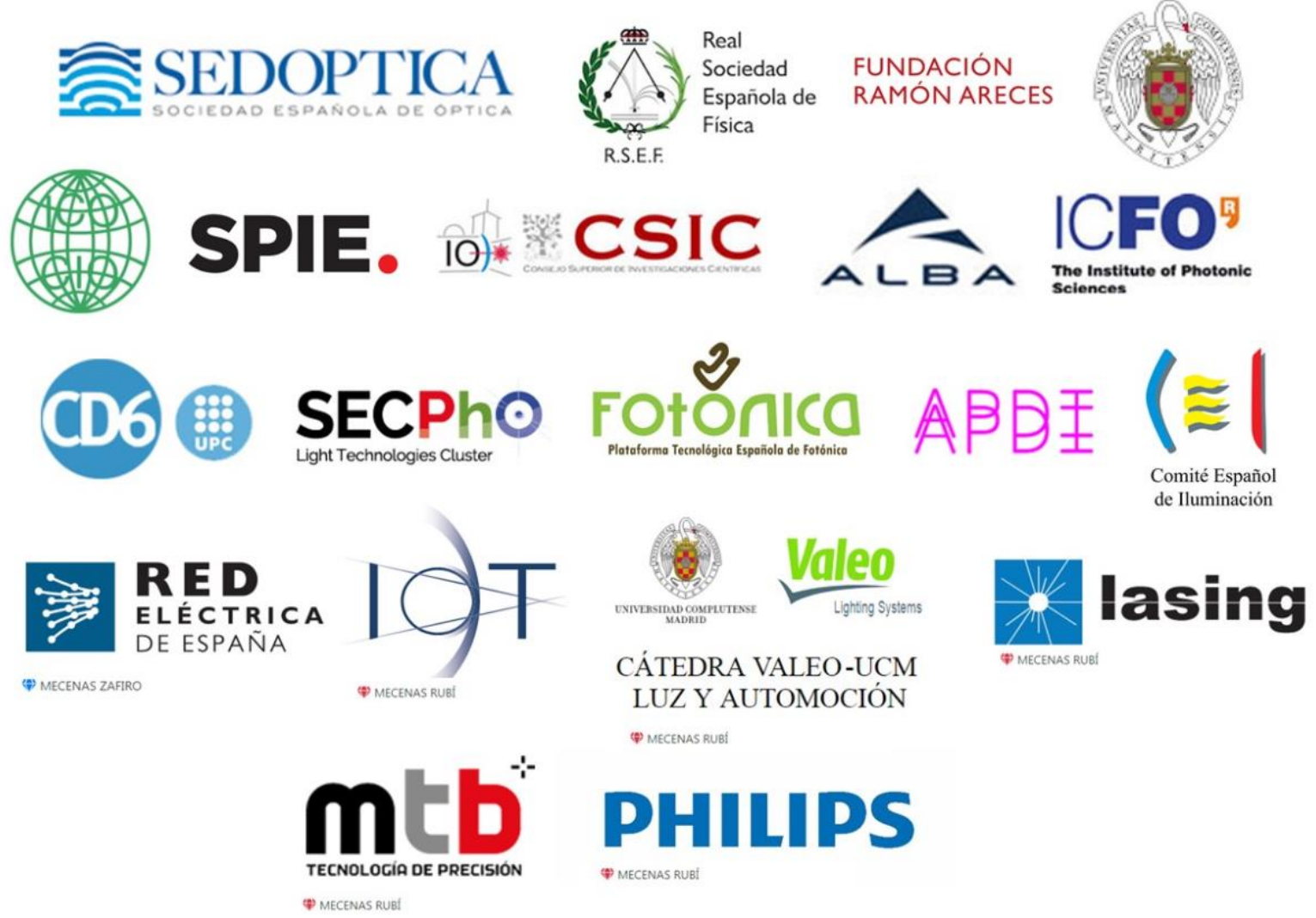

